\title{
Strategi Pengembangan Usaha Pembelian dan Penjualan Gabah UD.Gabah Indah (Studi Kasus) Kelurahan Takatidung Kecamatan Polewali Kabupaten Polewali Mandar
}

\author{
Takril*, Zulkifli Basri, Muh. Darwis.D. \\ Program Studi Agribisnis, Universitas Al Asyariah Mandar \\ *Korespondesi : takril@unsulbar.ac.id
}

\begin{abstract}
Abstrak
Penelitian dilaksanakan di UD. Gabah Indah selama 3 bulan dimulai dari bulan April sampai dengan Juni 2012 di Kelurahan Takatidung Kecamatan Polewali Kabupaten Polewali Mandar. Penelitian ini bertujuan untuk mengetahui analisa usaha serta strategi yang digunakan dalam menjalankan usaha di UD Gabah Indah. Metode penelitian yang digunakan adalah metode survey. Untuk menganalisa strategi pengembangan meggunakan SWOT dan kelayakan usaha menggunakan analisis pendapatan dan R/C Ratio. Hasil penelitian menunjukkan bahwa strategi matriks SWOT maka dapat disusun strategi yang sangat dibutuhkan untuk dapat meminimalisir kelemahan dan ancaman yang dihadapi oleh Bapak $\mathrm{H}$. Rasmo pada pengembangan usaha penjualan dan pembelian gabah, yaitu : (a) Meningkatkan pasokan gabah dan menjaga mutu gabah, untuk menjaga harga dan permintaan tetap tinggi dan (b) Menjalin kerjasama dengan pemerintah Kabupaten Polewali Mandar dalam hal informasi perluasan distribusi pemasaran gabah, sehingga konsumen/pelanggan semakin meningkat, dan dengan sendirinya pendapatan pun semakin meningkat.Untuk analisis usaha menunjukkan bahwa rata-rata sebesar Rp.431.016.341,- dari total rata-rata penerimaan sebesar Rp.6.822.000.000,- dan total biaya sebesar Rp.6.390.983.659,- sedangkan nilai R/C ratio yang diperoleh sebesar 1,1, sehingga usaha ini dapat dikatakan layak untuk tetap dikembangan.
\end{abstract}

Kata kunci : gabah; strategi; kelayakan usaha

\section{Pendahuluan}

Produksi padi Kabupaten Polewali Mandar tahun 2010 sebesar 225.092,00 ton yang dipanen dari areal seluas 32.966 ha atau rata-rata 6,8 ton per hektar. Produksi padi tahun pada 2010 mengalami kenaikan sebesar 14,90 persen dibandingkan dengan produksi pada tahun 2009 yang menghasilkan $195.906,00$ ton padi dengan luas panen 29,368 ha.( Anonim, 2010).menunjukkan bahwa luas lahan pertanian di Kecamatan Wonomulyo Kabupaten Polewali Mandar yaitu 33,215 ha. Hal ini merupakan salah satu faktor pendukung pengembangan usaha tani khususnya usahatani padi di Kelurahan Takatidung Kecamatan Polewali Kabupaten Polewali Mandar.luas tanam pada tahun 2007 - 2011 di Kabupaten Polewali Mandar sedikit mengalami kenaikan bahkan pada tahun 2011 luas tanam berkurang sampai 0,99\%, sedangkan pada tahun 2007 - 2009 luas tanam hampir tidak mengalami penurunan.

Jumlah produksi pun sangat berfariasi pada tahun 2007 produksi berkisar 203.968 ton, dan pada tahun 2008-2009 produksi menurun hingga mencapai 199.457 ton dan 190.678 ton, sedangkan pada tahun 2010-2011 produksi padi meningkat sebesar 0,87\% Dari hal tersebut maka perlu adanya perhatian yang lebih baik dari Pemerintah dalam hal ini menerapkan teknologi baru kepada petani, sehingga hasil produksi padi di Kabupaten Polewali Mandar semakin meningkat. Selain kebutuhan akan teknologi baru, penanganan pasca panen pun harus lebih maksimal, untuk itu petani harus segera menjual gabah hasil produksi mereka kepada pengusaha yang sudah menjadi mitra usaha dari petani itu sendiri, sehingga gabah hasil produksi tidak tersimpan dalam waktu yang cukup lama.

Berdasarkan latar belakang yang telah diuraikan di atas, maka perlu dilakukan suatu kajiandengan judul Strategi Pengembangan Usaha Pembelian dan Penjualan Gabah Pada UD.Gabah Indah (Studi Kasus) Kelurahan Takatidung Kecamatan Polewali Kabupaten Polewali Mandar.

\section{Metodologi}

Penelitian ini akan dilaksanakan pada UD. Gabah Indah selama 3 ( tiga) bulan dimulai dari bulan April sampai dengan Juni 2012 di Kelurahan Takatidung Kecamatan Polewali Kabupaten Polewali Mandar. Metode analisis data yang digunakan dalam penelitian ini adalah metode analisis kuantitatif yaitu untuk menentukan pendapatan dan tingkat kelayakan usaha UD. Gabah Indah dan Analisis SWOT yang merupakan salah satumetode untuk menggambarkan kondisi dan mengevaluasi suatu masalah UD Gabah Indah atau konsep bisnis yang berdasarkan faktor internal (dalam) dan faktor eksternal(luar) yaitu Strengths, Weakness, Opportunities dan Threats. 


\section{Analisis Data}

1.Analisis pendapatan,

$\mathrm{PD}=\mathrm{TR}-\mathrm{TC}$

$\mathrm{PD}=$ Pendapatan

$\mathrm{TR}=$ Total Penerimaan

$\mathrm{R}=$ Total Biaya

\section{Revenue Cost Ratio (R/C Ratio)}

Analisis R/C adalah singkatan dari Revenue Cost Ratio menurut Soekarwati (2006 : 85) untuk menganalisis kelayakan usaha apakah usaha ini memberikan keuntungan atau tidak, dapat digunakan rumus sebagai berikut :

$\mathrm{R} / \mathrm{C}$ ratio $=\underline{\text { Total Revenue }(\mathrm{TR})}$

Keterangan :

$$
\text { Total Cost (TC) }
$$

$\mathrm{R}=$ Penerimaan

$\mathrm{TC}=$ Biaya

Py = Harga output

$\mathrm{Y}=$ Output

$\mathrm{FC}=$ Biaya tetap

$\mathrm{VC}=$ Biaya variabel

Dengan kriteria :

a. Jika R/C $>1=$ Maka usaha tani tersebut dikatakan layak

b. Jika R/C $<1=$ Maka usaha tani tersebut dikatakan tidak layak

c. Jika $\mathrm{R} / \mathrm{C}=1 \quad=$ Impas

\section{Analisis $S W O T$}

Analisis SWOT merupakan salah satu metode untuk menggambarkan kondisi dan mengevaluasi suatu masalah, proyek atau konsep bisnis yang berdasarkan faktor internal (dalam) dan faktor eksternal (luar) yaitu Strengths, Weakness, Opportunities dan Threats. Metode ini paling sering digunakan dalam metode evaluasi bisnis untuk mencari strategi yang akan dilakukan. Analisis SWOT hanya menggambarkan situasi yang terjadi bukan sebagai pemecah masalah.

\section{Hasil dan Pembahasan}

\section{Sejarah Singkat UD. Gabah Indah}

UD. Gabah Indah didirikan oleh Bapak H. Rasmo pada tahun 2002 yang berlokasi di Kelurahan Takatidung. Bidang usaha yang digeluti adalah pembelian dan penjualan gabah. Merupakan salah satu usaha yang bergerak dalam UKM dengan memanfaatkan bahan baku gabah dari sektor pertanian. Tujuan untuk memenuhikebutuhan konsumen akan gabah dan untuk meningkatkan pendapatan kesejahteraan serta kemakmuran keluarga besar pendiri UD. Gabah Indah pada khususnya dan memberikan pelayanan yang memuaskan pada konsumen.

\section{Sumber Daya Manusia}

Sumber daya manusia yang dimiliki oleh UD. Gabah Indah sebanyak 14 orang yang terdiri dari (satu) orang direktur (pimpinan utama), 2 orang supir, 4 karenadan ke 6 orang tersebut dikatakan karyawan tetap, 4 orang karyawan lepas sekaligus mitra usaha
Bapak H. Rasmo. Untuk lebih jelasnyasecara rinci dapat dilihat pada Tabel 1 berikut:

Tabel 1.Keadaan Pengurus dan karyawan UD. Gabah Indah Di Kelurahan Takatidung Kecamatan Polewali Kabupaten Polewali Mandar, 2012

\begin{tabular}{lcccl}
\hline \multicolumn{1}{c}{ Nama } & $\begin{array}{c}\text { Umur } \\
\text { (tahun) }\end{array}$ & $\begin{array}{c}\text { Pendidi } \\
\text { kan }\end{array}$ & Posisi & Ket \\
\hline H. Rasmo & 45 & SMA & Direktur & Pemilik \\
Muis & 28 & SMP & Karyawan & Supir \\
Herman & 30 & SMP & Karyawan & Supir \\
Hadi & 37 & SD & Karyawan & Karne \\
Karim & 40 & SD & Karyawan & Karne \\
Gappar & 35 & SMP & Karyawan & Karne \\
Samad & 40 & SMP & Karyawan & Karne \\
Johan & 37 & SMP & Karyawan & Mitra \\
Husen & 57 & SD & Karyawan & Mitra \\
Jamal & 38 & SD & Karyawan & Mitra \\
\hline
\end{tabular}

Sumber : Data Primer Setelah Diolah, 2012

Berdasarkan Tabel 1 dapat di jelaskan bahwa tingkat umur rata-rata para pengurus dan karyawan (tenaga kerja) UD. Gabah Indah adalah berada pada tingkat atau kategori yang masih muda (30 - 57). Tingkat umur yang masih muda sangat memungkinkan untuk bekerja lebih produktif dalam mengelolah usahanya. Bila terlihat dari segi umur, maka UD. Gabah Indah memiliki peluang atau prospek yang besar untuk mengembangkan kegiatan usahanya. Untuk tingkat pendidikan memberikan gambaran bahwa tingkat pendidikan pengurus UD. Gabah Indah adalah rata-rata berada pada tingkat atau kategori sekolah lanjutan menengah yaitu SLTP hingga SLTA dan karyawannya berada pada tingkat pendidikan sekolah dasar (SD). Hal ini sudah dapat mendukung untuk meningkatkan produktifitas dan kemampuan kerja dalam menjalankan dan mengembangkan kegiatan usaha UD. Gabah Indah.

\section{Sumber Daya Finansial}

Tabel 2. Keadaan Sumber Daya Finansial Yang Dimiliki Oleh UD. Gabah Indah di Kelurahan Takatidung Kecamatan Polewali Kabupaten Polewali Mandar. 2012

\begin{tabular}{llr}
\hline No & Sumber daya & Nilai ( Rp ) \\
\hline 1 & Aktiva Tetap & \\
& a. Peralatan & 520.500 .000 \\
& b. Akm.Penyusutan & $(5.736 .159)$ \\
& $\quad$ Peralatan & 514.763 .841 \\
2 & Nilai Baku... & \\
& Aktiva lancar & 120.000 .000$. \\
& a. Kas & 72.500 .500 \\
& b. Stock Gabah & 192.500 .000 \\
& Jumlah aktiva Lancar & 707.263 .841 \\
\hline & Jumlah Aktiva Modal
\end{tabular}

Sumber : Data Primer Setelah Diolah, 2012 


\section{Sumber Daya Peralatan}

Tabel 3. Jenis, Jumlah, Nilai dan Lama Pemakaian Peralatan Pada UD. Gabah Indah di Kelurahan Takatidung Kecamatan Polewali Kabupaten Polewali Mandar, 2012

\begin{tabular}{|c|c|c|c|c|c|c|}
\hline \multirow{2}{*}{$\begin{array}{c}\text { Jenis } \\
\text { Peralatan }\end{array}$} & \multirow{2}{*}{$\Sigma$} & \multirow{2}{*}{$\begin{array}{c}\text { Nilai Awal } \\
(\mathbf{R p} / @)\end{array}$} & \multicolumn{2}{|c|}{ Total Nilai (Rp) } & \multirow{2}{*}{$\begin{array}{r}\text { Masa } \\
\text { Pakai } \\
- \text { (Thn) }\end{array}$} & \multirow{2}{*}{$\begin{array}{c}\text { Nilai } \\
\text { Penyusutan } \\
\text { (Rp/Bulan) }\end{array}$} \\
\hline & & & Awal & $\begin{array}{c}\text { Nilai Sisa } \\
(10 \%)\end{array}$ & & \\
\hline Mobil Mitsubisi & 1 & 17.000 .000 & 17.000 .000 & 1.700 .000 & 7 & 182.142 \\
\hline $\begin{array}{l}\text { Mobil Mitsubis } \\
125 \text { cc (Baru) }\end{array}$ & 1 & 230.000 .000 & 230.000 .000 & 23.000 .000 & 7 & 2.464 .285 \\
\hline $\begin{array}{l}\text { Mobil Turbo } \\
\text { (Baru) }\end{array}$ & 1 & 270.000 .000 & 270.000 .000 & 27.000 .000 & 7 & 2.892 .857 \\
\hline $\begin{array}{l}\text { Timbangan } \\
\text { Duduk }\end{array}$ & 3 & 7.500 .000 & 2.500 .000 & 250.000 & 4 & 140.625 \\
\hline $\begin{array}{l}\text { Timbangan } \\
\text { Berdiri } \\
\end{array}$ & 3 & 3.000 .000 & 1.000 .000 & 100.000 & 4 & 56.250 \\
\hline & Imlah & & $\mathbf{5 2 0 . 5 0 0 . 0 0 0}$ & 52.050 .000 & & 5.736 .159 \\
\hline
\end{tabular}

\section{Analisis Keuntungan Usaha Dan R/C Ratio Dalam Pembelian dan Penjualan Gabah.}

Adapun rata-rata penerimaan yang diperoleh Bapak H, Rasmo setiap bulannya pada pengembangan usaha pembelian dan penjualan gabah dapat dilihat pada Tabel 4 berikut ini :

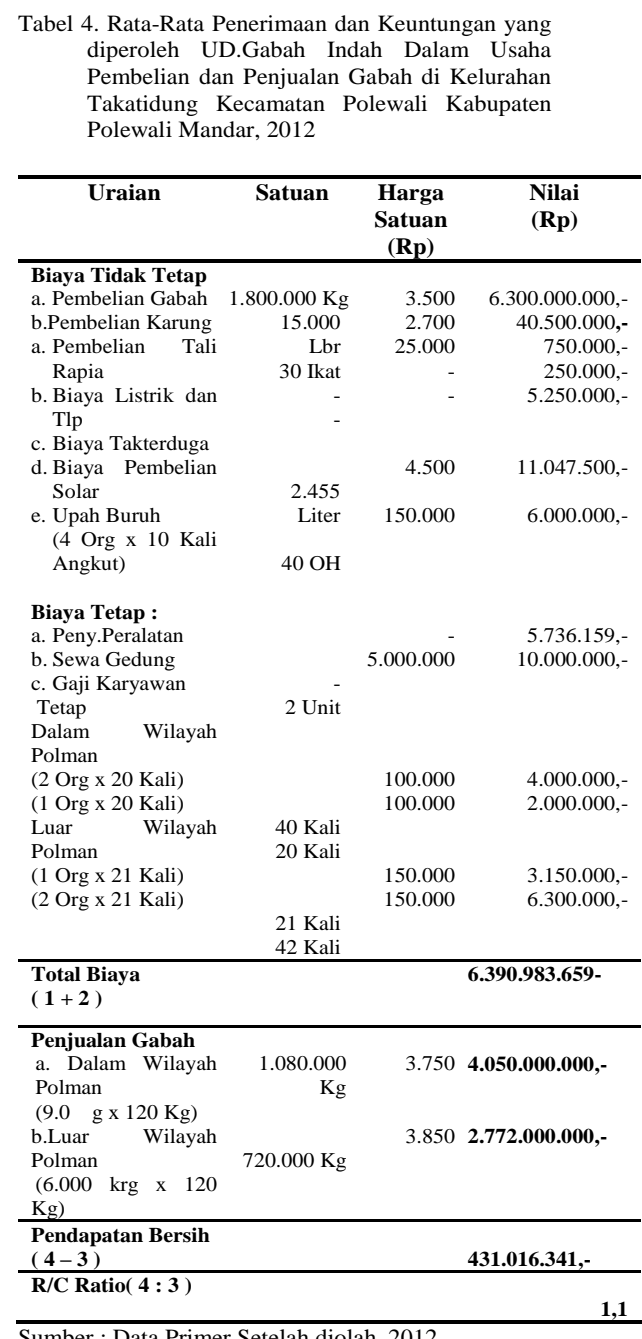

Berdasarkan Tabel 4 di atas menunjukkan bahwa rata-rata pendapatan yang diperoleh Bapak $\mathrm{H}$. Rasmo pada pengembangan usaha pembelian dan penjualan gabah sebesar Rp.431.016.341,- dari total rata-ratapenerimaansebesar Rp.6.822.000.000,- dan total biaya sebesar Rp.6.390.983.659,- sedangkan nilai $\mathrm{R} / \mathrm{C}$ ratio yang diperoleh sebesar 1,1 dimana setiap Rp.1,- input yang dikeluarkan akan memperoleh Rp.1,1,- output yang diperoleh, sehingga usaha ini dapat dikatakan layak untuk tetap dikembangan.

\section{Strategi Pengembangan Usaha pembelian dan penjualan gabah}

\begin{tabular}{|c|c|c|}
\hline $\begin{array}{l}\text { EFAS } \\
\text { Faktor Eksternal }\end{array}$ & $\begin{array}{l}\text { Kekuatan (Strenght) } \\
\text { - Modal tersedia } \\
\text { - Saprodi mudah } \\
\text { diperoleh } \\
\text { - Tenaga kerja } \\
\text { tersedia } \\
\text { - Pengalaman usaha } \\
\text { cukup baik } \\
\text { - Pemasaran yang } \\
\text { mudah }\end{array}$ & $\begin{array}{l}\text { Kelemahan } \\
\text { (Weakness) } \\
\text { - Produksi gabah yan } \\
\text { tidak } \\
\text { menentu. } \\
\text { - Distribusi pemasarar } \\
\text { yang masih sempit. } \\
\text { - Padi mudah di seran } \\
\text { penyakit } \\
\text { - Musim hujan di saa } \\
\text { panen. }\end{array}$ \\
\hline $\begin{array}{l}\text { Peluang }(\mathbf{O}) \\
\text { - Permintaan tinggi } \\
\text { - Harga relaif tinggi } \\
\text { - Hubungan yang } \\
\text { baik dengan } \\
\text { agen/pelanggan } \\
\text { tetap }\end{array}$ & $\begin{array}{l}\text { Strategi (SO) } \\
\text { - Memperbanyak } \\
\text { jumlah pasokan } \\
\text { gabah } \\
\text { - Menjaga hubungan } \\
\text { baik dengan } \\
\text { agen/pelanggan } \\
\text { tetap }\end{array}$ & $\begin{array}{l}\text { Strategi (WO) } \\
\text { - Meningkatkan dan } \\
\text { menjaga kualitas } \\
\text { gabah yang akan } \\
\text { dijual } \\
\text { - Menambah alat } \\
\text { pengangkutan dalam } \\
\text { hal perluasan jalur } \\
\text { distribusi/jalur } \\
\text { pemasaran }\end{array}$ \\
\hline $\begin{array}{l}\text { Ancaman (T) } \\
\text { - Musim hujan } \\
\text { - Adanya } \\
\text { persaingan } \\
\text { - Kendala wadah } \\
\text { dalam } \\
\text { menyimpang } \\
\text { gabah, Di saat } \\
\text { musim hujan. }\end{array}$ & $\begin{array}{l}\text { Strategi (ST) } \\
\text { - Meningkatkan } \\
\text { kuantitas gabah } \\
\text { untuk menjaga } \\
\text { persaingan } \\
\text { pelanggan dan } \\
\text { konsumen } \\
\text { - Menyediakan atau } \\
\text { menambah sumber } \\
\text { daya } \\
\text { manusiadalam } \\
\text { proses pembelian } \\
\text { dan penjualan } \\
\text { gabah. }\end{array}$ & $\begin{array}{l}\text { Strategi (WT) } \\
\text { - Bekerjasama dengan, } \\
\text { pemerintah dalam hal } \\
\text { perluasan distribus } \\
\text { pemasaran gabah }\end{array}$ \\
\hline
\end{tabular}

Sumber : Data Primer, 2012

Berdasarkan strategi matriks SWOT maka dapat disusun strategi yang sangat dibutuhkan untuk dapat meminimalisir kelemahan dan ancaman yang dihadapi oleh Bapak H. Rasmo pada pengembangan usaha penjualan dan pembelian gabah, yaitu :

1. Meningkatkan pasokan gabah dan menjaga mutu gabah, untuk menjaga harga dan permintaan tetap tinggi.

2. Menjalin kerjasama dengan pemerintah Kabupaten Polewali Mandar dalam hal informasi perluasan distribusi pemasaran gabah, sehingga konsumen/pelanggan semakin meningkat, dan dengan sendirinya pendapatan pun semakin meningkat. 


\section{Kesimpulan Dan Saran}

1. Strategi kekuatan yang dimiliki Bapak H. Rasmo dalam pengembangan usaha pembelian dan penjualan gabah adalah dengan adanya modal, saprodi mudah diperoleh, tenaga kerja yang tersedia, sedangkan kelemahan yang dimiliki adalah kurangnya tempat/wadah dalam penyimpangan gabah pada saat musim hujan, peluang yang dimiliki oleh Bapak H. Rasmo adalah hubungan yang baik dengan pelanggan.

2. Strategi yang dapat diambil oleh bapak H. rasmo dalam mengembangkan usaha pembelian dan penjualan gabah di kelurahan Takatidung adalah meningkatkan pasokan gabah dan menjaga kualitas dan kuantitas gabah.

3. Hasil penelitian menunjukkan bahwa rata-rata pendapatan yang diperoleh Bapak H. Rasmo pada pengembangan usaha pembelian dan penjualan gabah sebesar Rp.431.016.341,- dari total ratarata penerimaan sebesar Rp.6.822.000.000,- dan total biaya sebesar Rp.6.390.983.659,- sedangkan nilai $\mathrm{R} / \mathrm{C}$ ratio yang diperoleh sebesar 1,1 dimana setiap Rp.1,- input yang dikeluarkan akan memperoleh Rp.1,1,- output yang diperoleh, sehingga usaha ini dapat dikatakan layak untuk tetap dikembangan.

\section{Saran}

1. Pemerintah sebaiknya memberikan informasi yang lebih banyak kepada seluruh pelaku usaha dalam hal perluasan dsitribusi pemasaran gabah, sehingga para pelaku usaha lebih dapat memperluas jaringan pemasaran, dan dengan itu pula pendapatan para pelaku usaha semakin meningkat.

2. Diharapkan melakukan penelitian lebih lanjut terhadap perkembangan usaha pembelian dan penjualan gabah.

3. UD. Gabah Indah diharapkan lebih meningkatkan mutu / kualitas dan kuantitas gabah dalam menjaga harga tetap tinggi.

\section{Daftar Pustaka}

Anonim. 2007. Polewali Dalam Angka. Kabupaten Polewali Mandar

Anonim 2007.Badan Pusat Statistik ( BPS ) Prov. SulSel 2007. Makassar

Anonim 2007.Tentang Harga Pembelian Pemerintah (HPP).Makassar

Anonim 2009. Tentang Harga Pembelian Pemerintahan ( HPP ). Jawa Barat

Bustanul, A. 2005. Pembangunan Pertanian: Paradigma Kebijakan dan Strategi Revitalisasi, Grasido, Jakarta.
Dinas Pertanian dan Peternakan 2011. Produksi Padi Sawah Kabupaten Polewali Mandar

http://www. wikipedia.org. Kabupaten Polewali Mandar.Tanggal 25 Februari 2012

M.P Simangunsong (2004 : 6). Konsep Pendapatan Nasional. Surakarta

Samsuddin, S. 2006. Manajemen Sumber Daya Manusia. Pustaka Setia. Bandu

Soekartawi (2006:58) Analisis usaha. Universitas Indonesia ( UI-Press) Jakarta. 